\title{
Acute liver failure from Wilson's disease in a five-year-old child
}

\author{
N KALACH, MD, EG SEIDMAN, MDCM, C MORIN, MD, A RASQUIN-WEBER, MD, S O'REGAN, MD, \\ JM LABERGE, MDCM, H BLANCHARD, MD, P RUSSO, MDCM, K PARADIS, MDCM
}

N KALACH, EG SEIDMAN, C MORIN, et al. Acute liver failure from Wilson's disease in a five-year-old child. Can J Gastroenterol 1993;7(8):610-612. A five-year-old child presented with acute liver failure with jaundice, hemolysis, ascites, encephalopathy and coagulopathy. A diagnosis of fulminant Wilson's disease was made on the basis of elevated serum and urinary copper, and the simultaneous diagnosis of Wilson's disease in an older sibling. Despite supportive therapy, liver function remained precarious and the patient underwent a successful orthotopic liver transplant. This is one of the youngest children reported with fulminant liver failure from Wilson's disease and underlines the need to entertain the diagnosis in children presenting with liver failure even at this early age.

Key Words: Hemofiltration, Liver failure, Liver transplantation, Wilson's disease

\section{Insuffisance hépatique due à la maladie de Wilson chez un enfant de cing ans}

RÉSUMÉ : Un enfant de cinq ans a été admis en insuffisance hépatique aiguë, avec ictère, hémolyse, ascite, encéphalopathie et coagulopathie. Un diagnostic de maladie de Wilson fulminante a été posé sur la base des taux élevés de cuivre sanguin et urinaire et d'un diagnostic simultané de maladie de Wilson dans la fratrie. En dépit d'un traitement d'appoint, la fonction hépatique est demeurée précaire et le patient a subi avec succès une transplantation hépatique orthotopique. Il s'agit là de l'un des plus jeunes enfants chez qui une insuffisance hépatique fulminante due à la maladie de Wilson ait été diagnostiquée et souligne le besoin de soupçonner cette entité clinique chez les enfants, même jeunes, qui se présentent en insuffisance hépatique.

Division of Gastroenterology and Nutrition, Division of Nephrology, Department of

Pediatrics, Departments of Surgery and Pathology, Hôpital Ste-Justine, Université de Montréal, Montréal, Québec

Correspondence and reprints: Dr Khazal Paradis, Hôpital Ste-Justine, 3175 chemin de la Côte Ste-Catherine, Montréal, Québec H3T IC5

Received for publication November 25, 1992. Accepted April 5, 1993
W ILSON'S DISEASE IS AN AUTOSOmal recessive disorder of copper metabolism in which copper is deposited in numerous tissues, including the liver, central nervous system, kidneys, eyes and other organs. Teenagers and young adults may rarely present with a picture comprised of liver failure, hemolysis, renal insufficiency and death (1). The youngest reported cases with such a fulminant presentation were at age fiveand-one-half years $(2-4)$. The authors describe the case of a five-year-old child who presented with acute liver failure requiring liver transplantation despite establishment of appropriate therapy within weeks of presentation.

\section{CASE HISTORY}

The patient was a previously healthy five-year-old girl of nonconsanguinous French-Canadian ancestry who presented with intermittent episodes of vomiting, malaise and anorexia of a few weeks duration. Diarrhea and jaundice ensued, leading her to seek medical attention. Her growth was along the 90th percentiles for height and weight, and there was no history of exposure to toxins, medication or to other icteric individuals. Her diet was 
normally varied with no particular excessive consumption of copper-containing foods, and tap water contained trace levels of copper. In view of progression of jaundice and the appearance of ascites and lethargy she was transferred to our institution for further investigation.

On admission two weeks later, the patient was noted to be markedly icteric and irritable, with mild dehydration and normal vital signs. Abdominal exam revealed an enlarged, firm liver palpable $4 \mathrm{~cm}$ below the right costal margin, with a spleen tip and ascites. There were no spider angiomata, clubbing, palmar erythema nor evidence of venous collaterals. Neurological examination aside from irritability was within normal limits without other overt signs of encephalopathy.

Laboratory tests revealed marked hyperbilirubinemia, anemia and moderately elevated transaminase levels (Table 1). Liver synthetic function was markedly diminished, with coagulopathy (factor V of 30\%) and hypoalbuminemia. Renal function was normal. Active hemolysis was evident, but indirect and direct Coombs tests were negative. Serology for hepatitis A, $\mathrm{B}$ and $\mathrm{C}$, cytomegalovirus and Epstein Barr viruses were all negative. Ceruloplasmin was within the normal range at $249 \mathrm{mg} / \mathrm{L}$ (normal 240 to 420 ) and no Kayser-Fleischer rings were seen on slit-lamp examination.

Family history revealed that the patient's 15-year-old brother had recently developed dysarthria after having had tremors of several months duration with decreasing scholastic performance. A serum and urinary copper level was immediately obtained for our patient to confirm the suspicion of Wilson's disease; serum copper level was twice the upper limit of normal and $24 \mathrm{~h}$ urinary copper over 200 times normal (Table 2). Wilson's disease was simultaneously confirmed in her brother - his liver biopsy revealed a copper content of 560 $\mu \mathrm{g} / \mathrm{g}$ dry weight (normal 10 to 35 ) - and he was started on D-penicillamine.

Despite aggressive supportive therapy with transfusions of plasma and packed red blood cells, diuretics, neomycin and lactulose, the patient's

TABLE 1

Serum biochemistry and coagulation profile pre- and post live transplantation

\begin{tabular}{|c|c|c|c|c|c|c|}
\hline & \multirow[b]{2}{*}{ Normal values } & \multirow[b]{2}{*}{ Day 1} & \multirow[b]{2}{*}{ Day $15^{*}$} & \multirow[b]{2}{*}{ Day 50} & \multicolumn{2}{|c|}{ Post transplantation } \\
\hline & & & & & Day 15 & Day 30 \\
\hline AST & 11 to $43 \mathrm{IU} / \mathrm{L}$ & 245 & 190 & 345 & 33 & 35 \\
\hline ALT & 0 to $25 \mathrm{IU} / \mathrm{L}$ & 172 & 25 & 262 & 44 & 40 \\
\hline GGT & 3 to $16 \mathrm{IU} / \mathrm{L}$ & 290 & - & - & 197 & - \\
\hline Alkph & 80 to $330 \mathrm{IU} / \mathrm{L}$ & - & - & 324 & 157 & 249 \\
\hline $\begin{array}{l}\text { Bllirubin: } \\
\quad \text { total/direct }\end{array}$ & $\begin{array}{c}0 \text { to } 14 / \\
0 \text { to } 4 \mu \mathrm{mol} / \mathrm{L}\end{array}$ & $35 / 15$ & $256 / 115$ & $399 / 293$ & $16 / 17$ & $7 / 3$ \\
\hline Hemofiltration & 11.5 to $15.5 \mathrm{~g} / \mathrm{dL}$ & 11.8 & 7.3 & 8.2 & 11 & 12 \\
\hline Platelets & 130 to $440 \mathrm{~m} / \mathrm{mL}$ & 281,000 & 392,000 & 94,000 & 221,000 & 369,000 \\
\hline Total protein & 60 to $78 \mathrm{~g} / \mathrm{L}$ & - & 58 & 49 & 57 & 72 \\
\hline Albumin & 39 to $50 \mathrm{~g} / \mathrm{L}$ & - & 25 & 22 & 33 & 45 \\
\hline Urea & 2.5 to $7 \mathrm{mmol} / \mathrm{L}$ & - & 3.4 & 5.2 & 5.3 & 3 \\
\hline Creatinine & 40 to $130 \mu \mathrm{mol} / \mathrm{L}$ & - & 57 & 54 & 49 & 53 \\
\hline Ammonia & $<88 \mu \mathrm{mol} / \mathrm{L}$ & - & 52 & 65 & - & - \\
\hline Prothrombin time & Patient/control & $15 / 11$ & $17 / 11$ & $34.6 / 11.9$ & $12 / 11$ & - \\
\hline $\begin{array}{l}\text { Partial thrombo- } \\
\text { plastin time }\end{array}$ & Patient/control & $60 / 30$ & $60 / 30$ & $96 / 21.1$ & $32.5 / 29$ & - \\
\hline Factor V & $>70 \%$ & - & $30 \%$ & $17 \%$ & - & 92 \\
\hline
\end{tabular}

ALT Alanine aminotransferase: Alk ph Alkaline phosphatase; AST Asparate aminotransferase; GGT $\gamma$-glutamyl transpeptidase; PT Prothrombin time; PT Partial thromboplastin time; "Admission

course deteriorated, with development of progressive somnolence, agitation, tremor and confusion, and hyperrefluxia, anasarca with pleural effusions and fetor hepaticus over the course of 10 days. Post dilution hemofiltration was initiated to attempt to decrease the serum copper load. Although little copper appeared to be removed with this manoeuvre (Table 2), hemolysis subsided and oral D-penicillamine was gradually introduced $(1.25 \mathrm{mg} / \mathrm{kg} /$ day to a full dose of $20 \mathrm{mg} / \mathrm{kg} /$ day) one week after admission when vomiting subsided.

Although her general clinical condition improved, the liver failure remained unchanged. She was placed on the liver transplant waiting list and 52 days after admission underwent a successful ABO-compatible liver transplant using a reduced-size adult liver. The resected liver weighed $878 \mathrm{~g}$ with markedly nodular bile-stained surfaces. Histology revealed macro- and micronodular cirrhosis with large septa containing inflammatory cells and neoductular proliferation. Nonstaining was seen in hepatocytes, Kupffer cells and particularly in proliferating ductules. Hepatic copper concentration was 948 $\mu \mathrm{g} / \mathrm{g}$ dry weight (normal less than 50 ). Serum and urinary copper levels re-
TABLE 2 Copper studies

\begin{tabular}{lcc}
\hline $\begin{array}{l}\text { Hospital } \\
\text { day }\end{array}$ & $\begin{array}{c}\text { Serum } \\
\text { copper } \\
\text { concentration }\end{array}$ & $\begin{array}{c}\text { 24 h urinary } \\
\text { copper } \\
\text { concentration }\end{array}$ \\
\hline 1 & 45.90 & 112.6 \\
3 & 49.70 & - \\
4 & 30.00 & - \\
5 & 28.70 & - \\
$6^{\dagger}$ & 29.50 & - \\
$7^{\dagger}$ & 34.20 & - \\
8 & 30.30 & - \\
10 & 30.50 & - \\
11 & 34.90 & - \\
32 days PT & 12.35 & 0.59 \\
$n$ & 12.2 to $29^{*}$ & $<0.62^{\dagger}$ \\
\hline
\end{tabular}

${ }^{\mu} \mu \mathrm{mol} / \mathrm{L} ;{ }^{\dagger} \mu \mathrm{mol} / 24 \mathrm{~h} ;{ }^{\dagger}$ During hemofiltration: $n$ Normal values; PT Post transplant

turned to normal within a month after transplantation.

\section{DISCUSSION}

Although the basic mechanism underlying the excessive copper deposits in Wilson's disease remains to be discovered, there have been considerable advances in the diagnosis, genetics and therapy of this disorder in the past few decades. The clinical presentation of liver disease ranges from subclinical (asymptomatic elevation of transami- 
nases) to overt in approximately $40 \%$ of patients. The latter is characterized by portal hypertension, jaundice, ascites, spontaneous peritonitis and encephalopathy. This type of presentation has been described as not occurring prior to age five years $(1,2)$. Onset with fulminant liver failure in the pediatric age group, as seen in the present case, usually is fatal and usually occurs in late childhood or early adolescence (1-4).

The diagnosis of Wilson's disease in younger children with fulminant disease is difficult, as Kayser-Fleischer rings are often absent, neurological disease is not yet evident and ceruloplasmin levels may be normal (as seen in our patient). Urinary copper altering penicillamine challenge is possibly one of the most reliable diagnostic indicators for Wilson's disease (5). Furthermore, a liver biopsy for copper level determination may be precluded due to the associated coagulopathy, and serum copper levels may be within the normal range $(3,4,6)$. Thus the diagnosis rests on extremely elevated cupruria as in our patient with or without elevated serum copper (6) or by a radiocopper loading test (7). This latter test was not considered necessary in our case as further support for the probability of Wilson's disease had been obtained with the diagnosis of Wilson's disease in her

ACKNOWLEDGEMENTS: The authors thank Dr Irmin Sternlieb for generous advice and for the copper determination on the patients's resected liver.

\section{REFERENCES}

1. Roche-Sicot J, Benhamou JP. Acute intravascular hemolysis and acute liver failure associated as a first manifestation of Wilson's disease. Ann Intern Med 1977;86:301-3.

2. Kraut JR, Yogev R. Fatal fulminant hepatitis with hemolysis in Wilson's disease. Clin Pediatr 1984;23:637-40.

3. Sternlieb I. Perspectives on Wilson's disease. Hepatology 1990;12:1234-9.

4. Walia BNS, Singh S, Marwaha RK, Bhusnurmath SR, DiLawari JB. Fulminant hepatic failure and acute intravascular haemolysis as presenting manifestations of Wilson's disease in young children. J Gastroenterol Hepatol 1992;7:370-3. brother, as well as the very elevated serum copper levels and cupruria.

Management of fulminant Wilson's disease may be difficult. Plasmapheresis as well as post dilution hemofiltration have yielded conflicting results (8-10). In our patient, these procedures removed insignificant amounts of copper. The fact that hemolysis subsided during hemofiltration in our patient was more likely a coincidence, while the removal of copper from her diet as well as the massive amounts of copper excreted in her urine probably contributed more significantly to her improvement. It remains unclear whether D-penicillamine contributed to her stabilization, allowing us to wait for a suitable $\mathrm{ABO}$ compatible liver (however, it did further accelerate the urinary copper excretion).

Berman et al (11) have suggested that a ratio of alkaline phosphatase to total serum bilirubin of less than 2 and an asparate aminotransferase to alanine aminotransferase ratio of greater than 4 may be useful in differentiating fulminant Wilson's disease from other causes of fulminant liver disease. In our patient, these ratios were only sometimes suggestive of Wilson's disease depending on the date at which these were done (Table 1). Similarly, Walia and co-workers (4) did not find these ratios

\section{Martins da Costa C, Baldwin D,}

Fortmann B, Lolin Y, Mowat AP, Mieli-Vergagni G. Value of urinary copper excretion alter penicillamine challenge in the diagnosis of Wilson's disease. Hepatology 1992;15:609-15.

6. McCullough AJ, Fleming CR, Thistle JL, et al. Diagnosis of Wilson's disease presenting as fulminant hepatic failure. Gastroenterology 1983;84:161-7.

7. Sternlieb I, Scheinberg IH. The role of radiocopper in the diagnosis of Wilson's disease. Gastroenterology 1979;7:138-42.

8. Denis J, Guerin JM, Opolon P, Huguet C, Levy VG, Poupon R.

Hemofiltration with a high permeability membrane in the treatment of fulminant or end-stage Wilson's disease. ASAIO J 1983;6:36-43.

9. Rakela J, Kurtz SB, McCarthy JT, et al. to be of benefit in their three pediatric cases. It may be that the manifestations of Wilson's disease in children are such that these ratios may not be as useful as in the adult population.

The indication for liver transplantation in Wilson's disease remains the same as for other chronic liver diseases - deterioration of liver synthetic function despite maximal medical therapy. Liver transplantation restores normal copper metabolism and provides a distinctly better outcome for those patients with clinical or subclinical liver failure from Wilson's disease than those patients treated with medical management alone $(12,13)$. There is no evidence that D-penicillamine therapy prevents the need for liver transplantation in patients with fulminant Wilson's disease.

The prevalence of Wilson's disease (being in the order of one in 30,000 ) is rare enough that it is often excluded from the differential diagnosis of fulminant liver disease, particularly in younger children (14). This case, one of the youngest presenting in this manner and the youngest to be transplanted for Wilson's disease to our knowledge, illustrates the need to include Wilson's disease as a distinct possibility in children presenting with liver disease even at this young age.

Fulminant Wilson's disease treated with postdilution hemofiltration and orthotopic liver transplantation. Gastroenterology 1986;90:2004-7.

10. Stampfl DA, Munoz SJ, Moritz MJ, et al. Heterotopic liver transplantation for fulminant Wilson's disease. Gastroenterology 1990;99:1834-6.

11. Berman DH, Leventhal RI, Gavaler JS, et al. Clinical differentiation of fulminant Wilsonian hepatitis from other causes of hepatic failure. Gastroenterology 1991;100:1129-34.

12. Sokol RJ, Francis PD, Gold SH, Ford DM, Lum GM, Ambruso DR. Orthotopic liver transplantation for acute fulminant Wilson's disease. J Pediatr 1985;107:549-52.

13. Sternlieb I. Wilson's disease: Indications for liver transplants. Hepatology 1984;4:15S-7S.

14. Scheinberg IH, Sternlieb I. Wilson's Disease. Philadelphia: WB Saunders, 1984. 


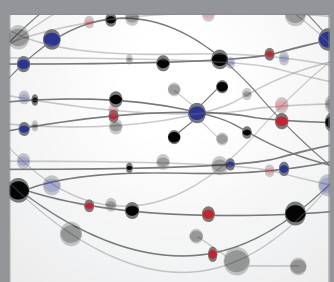

The Scientific World Journal
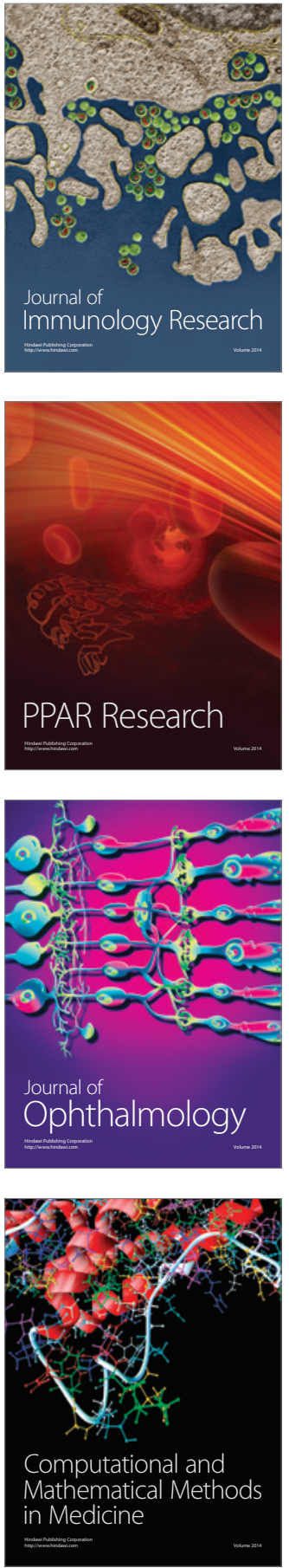

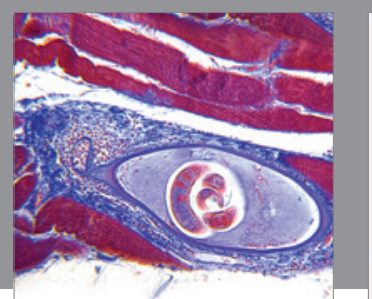

Gastroenterology Research and Practice

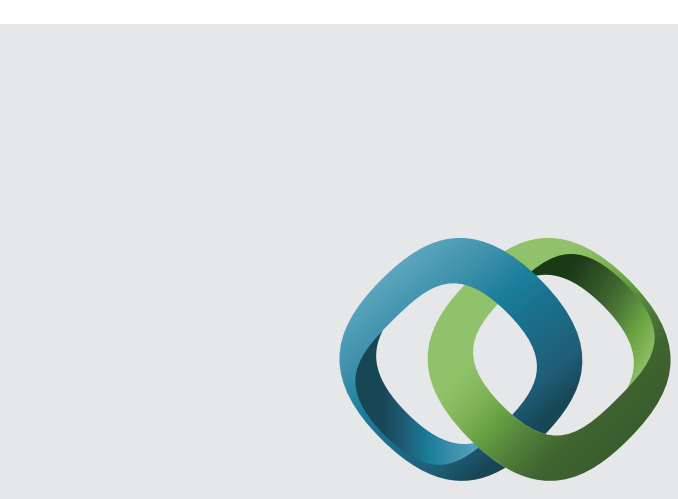

\section{Hindawi}

Submit your manuscripts at

http://www.hindawi.com
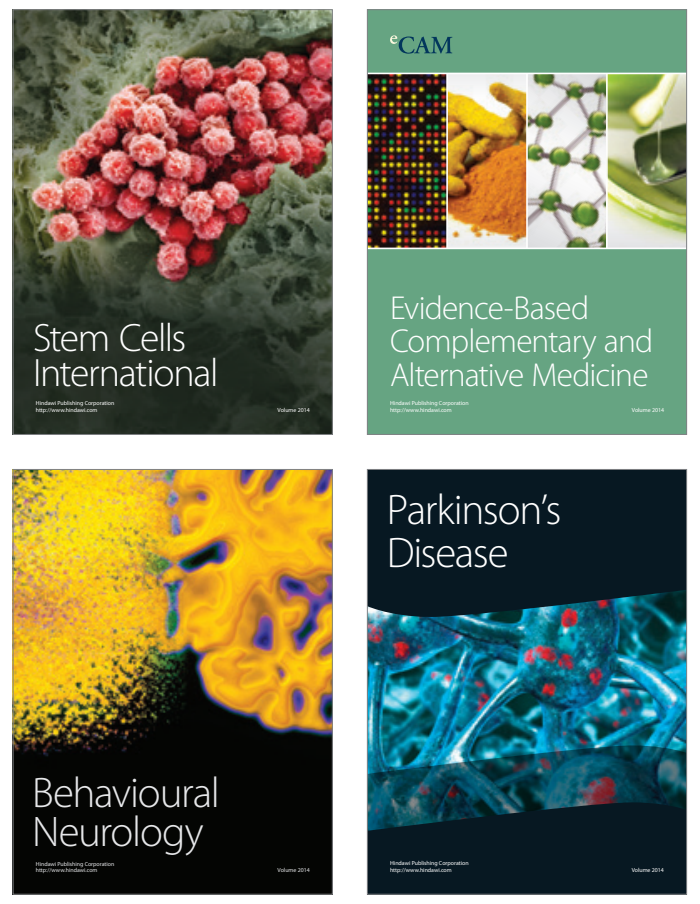
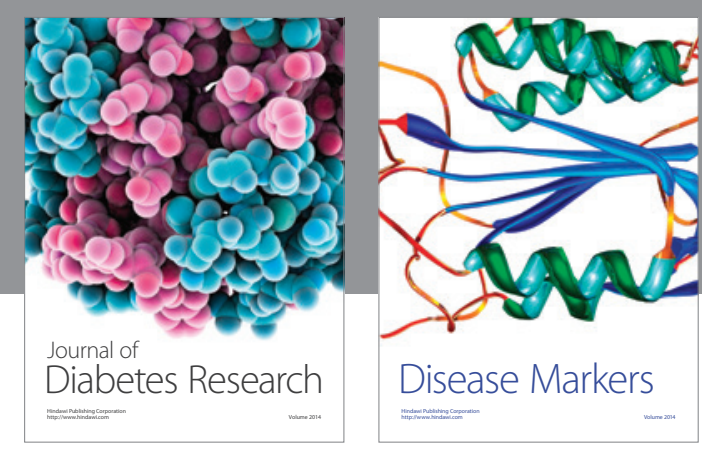

Disease Markers
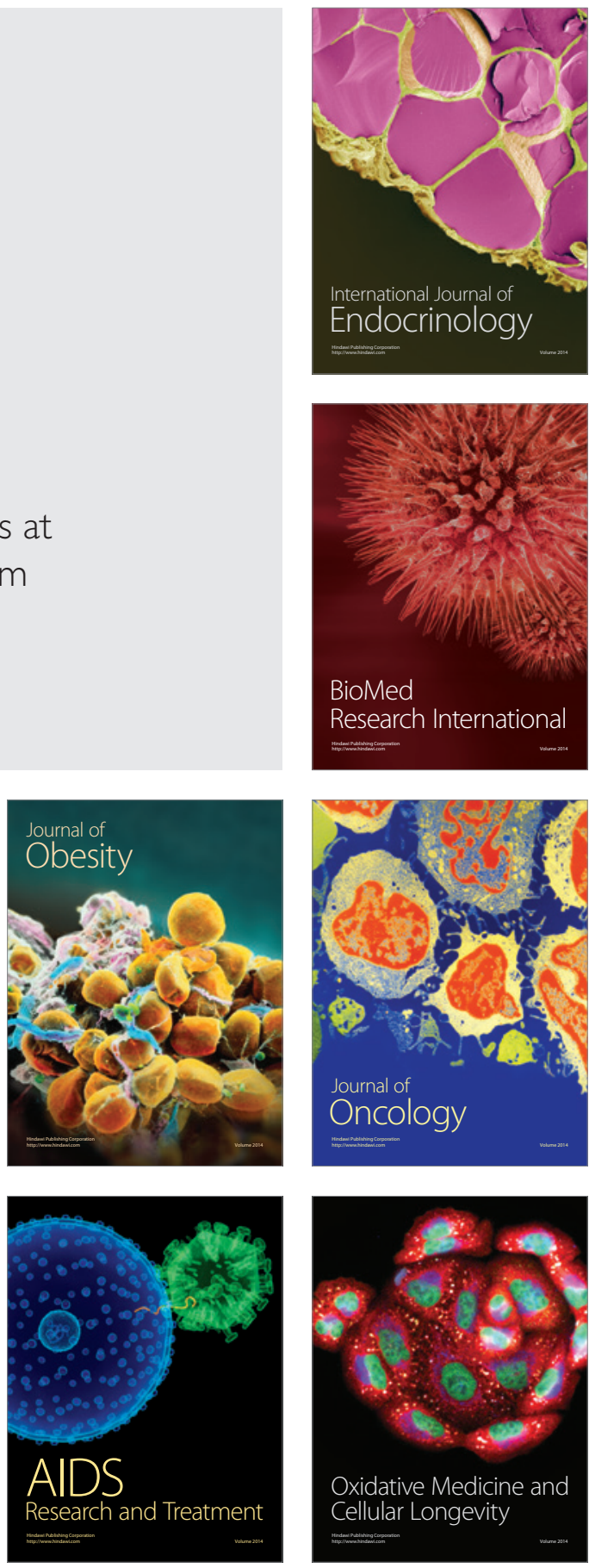